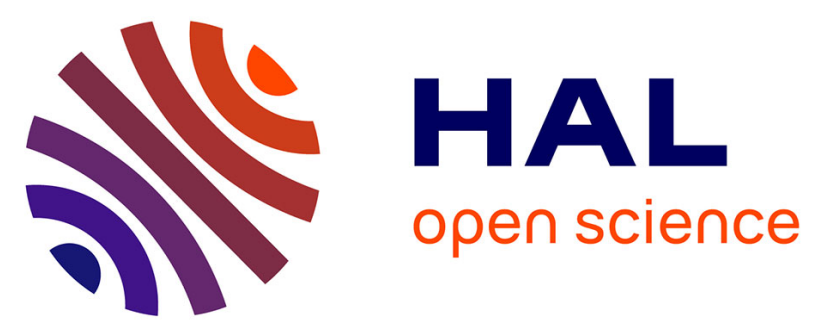

\title{
Dual Redox and Optical Control of Chiroptical Activity in Photochromic Dithienylethenes Decorated with Hexahelicene and Bis-Ethynyl-Ruthenium Units
}

Chengshuo Shen, Xiaoyan He, Loic Toupet, Lucie Norel, Stéphane Rigaut, Jeanne Crassous

\section{To cite this version:}

Chengshuo Shen, Xiaoyan He, Loic Toupet, Lucie Norel, Stéphane Rigaut, et al.. Dual Redox and Optical Control of Chiroptical Activity in Photochromic Dithienylethenes Decorated with Hexahelicene and Bis-Ethynyl-Ruthenium Units. Organometallics, 2018, 37 (5), pp.697-705. 10.1021/acs.organomet.7b00534 . hal-01586567

\section{HAL Id: hal-01586567 https://hal.science/hal-01586567}

Submitted on 29 Mar 2018

HAL is a multi-disciplinary open access archive for the deposit and dissemination of scientific research documents, whether they are published or not. The documents may come from teaching and research institutions in France or abroad, or from public or private research centers.
L'archive ouverte pluridisciplinaire HAL, est destinée au dépôt et à la diffusion de documents scientifiques de niveau recherche, publiés ou non, émanant des établissements d'enseignement et de recherche français ou étrangers, des laboratoires publics ou privés. 


\title{
Dual redox and optical control of chiroptical activity in photo- chromic dithienylethenes decorated with hexahelicene and bis-ethynyl-ruthenium units.
}

\author{
Chengshuo Shen, ${ }^{\dagger}$ Xiaoyan He ${ }^{\dagger}$ Loïc Toupet, ${ }^{\dagger}$ Lucie Norel, ${ }^{\dagger}$ Stéphane Rigaut,,${ }^{*} \dagger$ Jeanne Crassous ${ }^{*}, \dagger$ \\ ${ }^{\dagger}$ Institut des Sciences Chimiques de Rennes, UMR 6226, Institut de Physique de Rennes, UMR 6251, Campus de Beaulieu, \\ CNRS-Université de Rennes 1, 35042 Rennes Cedex, France \\ Supporting Information Placeholder
}

\begin{abstract}
We describe the synthesis of mono- and bis-([6]helicene=-Ru(dppe $\left.)_{2} \equiv\right)$-DTE complexes 1 o,c and 2o,c. The photochromic and electrochromic properties were studied and attractive isomerization processes were observed, ie. spontaneous reopening of $[1 \mathrm{c}]^{++}$to $[1 \mathrm{o}]^{+}$and ring closure of $[2 \mathrm{o}]^{2+}$ to $[2 \mathrm{c}]^{2+}$. Due to strong chiroptical responses, all these chiral complexes correspond to new types of chiroptical switches (triggered by light and/or redox stimuli) and could be described as either "NOR" or "OR" logic gates.
\end{abstract}

\section{INTRODUCTION}

Helicenes are molecules formed of ortho-fused aromatic rings that adopt a helical shape as a consequence of the steric hindrance between the terminal rings. ${ }^{1}$ Such an inherently chiral topology combined with an extended $\pi$-conjugation provides helicenes with huge optical rotation (OR) values ${ }^{1 \mathrm{~g}}$ intense electronic circularly dichroism (ECD) spectra ${ }^{2}$ substantial circularly polarized luminescence (CPL), under special circumstance described in the literature. ${ }^{3}$ As a result of this strong optical activity, helicenes may find applications as chiral molecular materials, ${ }^{4}$ especially as chiroptical switches, ${ }^{5,6}$ with potential interest as memory elements or logic operators, chiral sensors, encoding elements, switchable asymmetric catalysts or as unidirectional molecular motors. ${ }^{4 \mathrm{~b}, \mathrm{c}}$ Helicenes display several attractive features to be used as chiroptical switches, such as high thermal stability, higher solubility than more planar aromatic structures and large variations in electronic properties and chiroptical properties upon modification of $\pi$ conjugation. In the last decades several types of helicene-based chiroptical switches have been developed, for which the switching process is (i) mainly triggered by light, redox or acid/base stimuli, and (ii) read-out by using one of the chiroptical responses (OR, ECD, CPL). ${ }^{6}$

Among several kinds of photochromic units that can be applied for light-triggered switches, the most widely used is undoubtedly the dithienylethene unit (DTE). ${ }^{7}$ Few examples of DTE-based photo-active helicene molecules behaving as light-triggered chiroptical switches have already been described in the literature, ${ }^{8}$ such as for instance DTEs bearing two pinene derivatives, for which a stereoselective ring closing process resulted in a DTE-based thia[7]helicene with very large changes in optical rotatory dispersion (ORD) spectra between the open state and the closed photostationary state. ${ }^{8 c}$

On the other hand, carbon-rich electroactive ruthenium(II) complexes bearing one or two arylethynyl ligands have been widely studied, ${ }^{9}$ and can lead to efficient redox-triggered switches ${ }^{10}$ thanks to a reversible redox activity and strong changes in their optical response due to the non-innocent character of the arylethynyl chromophores. Such a concept has been applied by us in the chemistry of organometallic helicenes, notably by grafting on a carbo[6]helicene platform either vinyl-ruthenium or ethynyl-iron redoxactive species, and efficient redox-triggered chiroptical switches were obtained. ${ }^{6 a, d, e}$

The combination of a photochromic DTE units with redox-active $\mathrm{Ru}^{+/ 0}$ centers through a $\mathrm{C} \equiv \mathrm{C}$ bond can generate a multifunctional potential /light-triggered dual switching, either by stimulating oxidation states using a redox potential, or by stimulating the open/closed states from light irradiation. ${ }^{1 \text { la-d }}$ Because the DTE unit becomes a non-innocent ligand, the redox-state change may also have an influence on the closure/opening of the DTE unit. ${ }^{12}$ More specifically, in bimetallic complexes in which a dithienylethene (DTE) linker connects two ruthenium carbon-rich units, closing at remarkably low voltage (0.4-0.5 V vs SCE) is achieved and give rise to multicolor electrochromism. ${ }^{11 e}$ This behavior could be transferred to self-assembled monolayers to reach dual responsive surfaces ${ }^{11 \mathrm{f}}$ and exploited in the design of efficient multi-controllable molecular junctions in which both light and potential efficiently trigger the device response. ${ }^{11 g}$

In this article, we extend this concept for the first time to the dual redox and optical control of chiroptical activity by (i) describing the synthesis of enantiopure complexes $(\mathbf{1 o , c}$ and $\mathbf{2 o , c})$ consisting of ruthenium-bis-ethynyl complexes linked to helicene and DTE 
units, and (ii) studying in details their behavior as chiroptical switches due to the reversible ring DTE closure/opening triggered by an electrical potential and by UV or visible lights. Indeed, since helicenes display strong chiroptical responses, they provide with tags that can be used for reading out the system, especially by electronic circular dichroism.

\section{RESULTS}

\section{SYNTHESIS OF COMPLEXES 10 AND 20}

Two different systems were designed and are depicted in Chart 1 . Molecule 10 consists in a central trans-bis-ethynyl-Ru( $\eta^{2}$-dppe $)_{2}$ redox-active system (dppe:1,2-bis(diphenylphosphino)ethane) decorated on one side by an open photochromic DTE unit, and on the other side by an enantiopure carbo[6]helicene fragment. Molecule 20 includes a central open photochromic DTE unit linked to two trans-bis-ethynyl-Ru( $\eta^{2}$-dppe $)_{2}$ moieties, each terminated by an enantiopure carbo[6]helicene fragment.

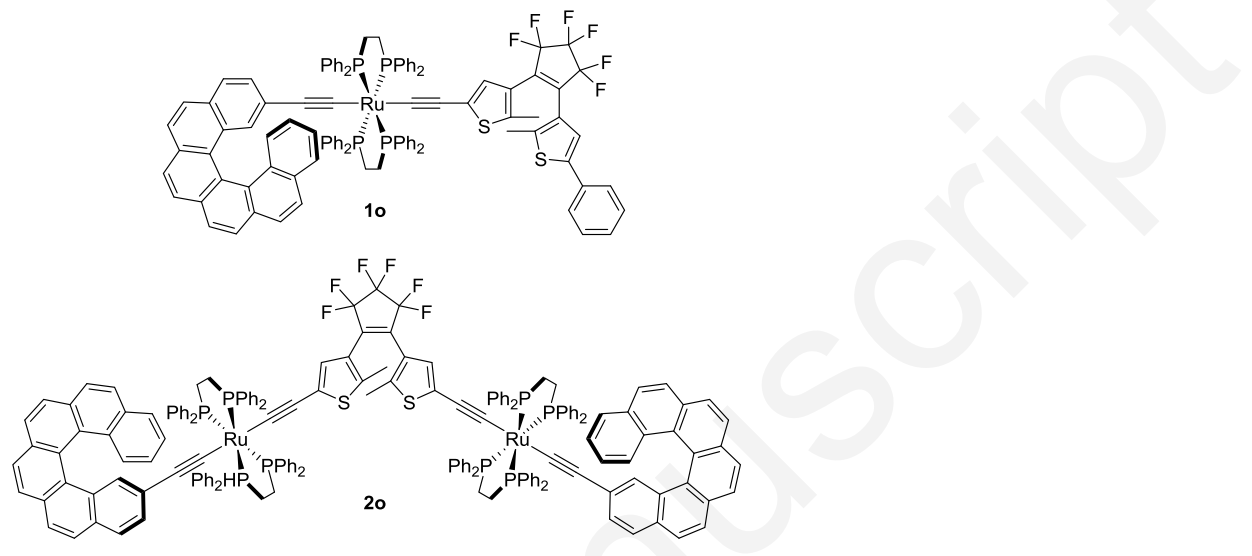

CHART 1. Chemical structure of the DTE based helicene-ethynyl-Ru switching systems ( $P$-1o and $(P, P)$-2o enantiomers shown).

The strategies for synthesizing molecules $\mathbf{1 0}$ and $\mathbf{2 0}$ are described in Scheme 1 . First, the 2-ethynyl[6]helicene ligand rac-, $P$ - or $M$ $3^{6 \mathrm{a}}$ was reacted with the 16-electron precursor $\left[\mathrm{Ru}\left(\eta^{2} \text {-dppe }\right)_{2} \mathrm{Cl}\right] \mathrm{OTf} \mathbf{4}$ in a degassed $\mathrm{CH}_{2} \mathrm{Cl}_{2}$ solution at $25^{\circ} \mathrm{C}$, yielding the cationic vinylidene complexes rac, $P$ - or $M-\mathbf{5}$, which was then reacted with mono-ethynyl DTE ligand $\mathbf{6 o}^{13}$ in the presence of $\mathrm{NaPF}_{6}$ and $\mathrm{NEt}_{3},{ }^{1 \mathrm{~d}-\mathrm{h}}$ to form respectively $\mathrm{rac}-, P$ - or $M$-1o as yellow solids, with overall yields between $73-84 \%$ (see Supplementary Information, SI). For the preparation of $(P, P)$ - or $(M, M)$-2o, DTE-bis-ethynyl-bis-ruthenium complex 80 was first obtained from the bisethynyl DTE 7o according to a literature procedure, ${ }^{11 \mathrm{~d}, \mathrm{e}}$ and was then reacted with 2 equivalents of $P$ - or $M-3$ under similar conditions as those used for 1o. Enantiopure $(P, P)$ - and $(M, M)$-2o were obtained as yellow solids with 58-69\% overall yields. Note that only enantiopure 3 was used here in order to avoid the formation of the meso compound. All these species were fully characterized by means of ${ }^{31} \mathrm{P},{ }^{1} \mathrm{H}$, and ${ }^{13} \mathrm{C}$ NMR spectroscopies and HR mass spectrometry. As an illustration, in the ${ }^{1} \mathrm{H}$ NMR spectrum of complex 1o, the helicene protons are mostly deshielded with chemical shifts around 7.6-8 ppm. The typical two $\mathrm{CH}_{3}$ groups from the DTE unit have distinct chemical shifts at 2.02 and $1.87 \mathrm{ppm}$. With ${ }^{13} \mathrm{C} \mathrm{NMR}$, the $\beta$-carbons from the two $\mathrm{C} \equiv \mathrm{C}$ bonds display chemical shifts at 119.24 and $107.19 \mathrm{ppm}$. The $\mathrm{CH}_{2}$ groups are diastereotopic owing to the presence of the chiral helicenic part, and were found as broad multiplets at 32.62 and $31.42 \mathrm{ppm}$. In the ${ }^{31} \mathrm{P}$ NMR spectrum, two signals were found at 54.44 and 51.38 ppm, respectively, as triplets (with a coupling constant of $23 \mathrm{~Hz}$ ), again due to their diastereotopic relationship. In the ${ }^{19} \mathrm{~F}$ NMR spectrum, each $\mathrm{CF}_{2}$ groups from the DTE unit show a distinct signal. The NMR spectra of $\mathbf{2 o}$ display the same general features, but are simplified due to a higher molecular symmetry $\left(C_{2} v s\right.$. $C_{1}$ for 1o). For instance, the protons of the typical two methyl groups from the DTE unit resonate at $1.86 \mathrm{ppm}$ (see SI).

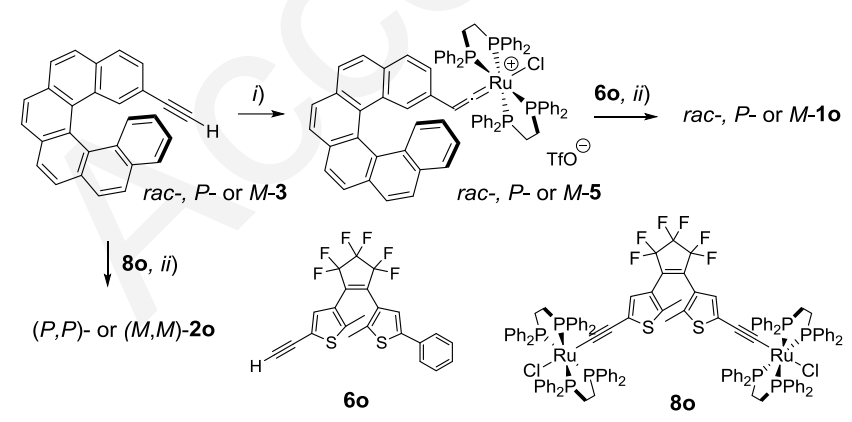

SCHEME 1 Synthesis of complex 1o and 2o. i) Ru(dppe) $\left.{ }_{2} \mathrm{Cl}\right] \mathrm{OTf}(4), \mathrm{CH}_{2} \mathrm{Cl}_{2}, 25^{\circ} \mathrm{C}, 16 \mathrm{hrs}, 87-96 \%$; ii) $\mathrm{NEt}_{3}, \mathrm{CH}_{2} \mathrm{Cl}_{2} \mathrm{NaPF}_{6}, 25^{\circ} \mathrm{C}, 48-72$ hrs, $82-96 \%$; iii) $4, \mathrm{CH}_{2} \mathrm{Cl}_{2}, 25^{\circ} \mathrm{C}, 4$ days; then $\mathrm{NEt}_{3}, \mathrm{CH}_{2} \mathrm{Cl}_{2}, 30 \mathrm{~min}, 58-69 \%$. 
Deep yellow single crystals of $\mathrm{rac}$-10 were grown by diffusion of pentane vapors into a $\mathrm{CH}_{2} \mathrm{Cl}_{2}$ solution in the dark and the crystal structure was characterized by X-ray diffraction. Complex rac-1o crystallized in the centrosymmetric $P \overline{1}$ space group (Figure 1). From the structure, the ruthenium center displays a distorted octahedral geometry, with the two $\mathrm{C} \equiv \mathrm{C}$ bonds in mutually transpositions. Distortion along the $\mathrm{C} \equiv \mathrm{C}$ bond of the helicene unit was observed. Indeed, compared with the angles along $\mathrm{Ru}-\mathrm{C} \equiv \mathrm{C}-\mathrm{DTE}(\mathrm{Ru} 1-\mathrm{C} 81-\mathrm{C} 82$ and $\mathrm{C} 81-\mathrm{C} 82-\mathrm{C} 83)$ almost close to $180^{\circ}$, the angles along $\mathrm{Ru}-\mathrm{C} \equiv \mathrm{C}-[6]$ helicene show large deviations, especially the $\mathrm{C} 1-\mathrm{C} 2-\mathrm{C} 3$ angle being around $167^{\circ}$. This is probably caused by the steric hindrance between the [6] helicene unit and dppe ligands. The average number between the four angles of $\mathrm{P}-\mathrm{Ru} 1-\mathrm{C} 1$ is $91.6^{\circ}$, which is larger than the average number $88.4^{\circ}$ of $\mathrm{P}-\mathrm{Ru} 1-\mathrm{C} 81$, indicating that the four $\mathrm{P}-\mathrm{Ru}$ bonds diverge from the octahedral positions and slope slightly to the DTE side. Besides, the helicity (dihedral angle between two terminal helicene rings) of the helicene unit is $45.1^{\circ}$, and com-

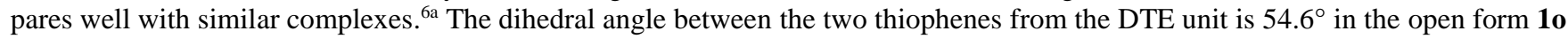
due to the steric hindrance from the two methyl groups. Finally, we also clearly found that although the compound crystallized in the racemic form, the stereochemistry of photoreactive anti-parallel open DTE unit is related with the stereochemistry of the helicene in the solid state: they show the same chirality in one molecule, i.e. when the chirality of helicene is $M$, the chirality of open DTE unit is also $M$ (vide infra).

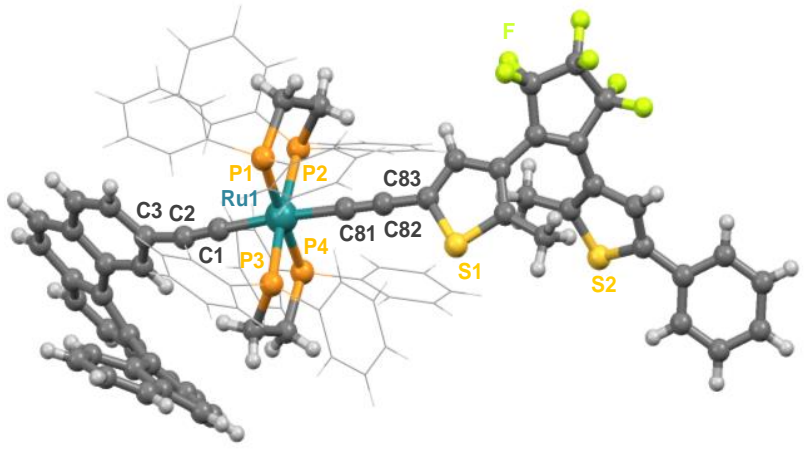

FIGURE 1. X-ray crystallographic structure of 10 (only $P$ enantiomer is shown; the 8 phenyl groups from dppe ligands are shown in wireframe style for clarity).

\section{SWITCHING ACTIVITY OF COMPLEX 10/C \\ PHOTOCHROMIC PROPERTY}

The light-triggered switching property of 10 was studied first. Upon irradiation at $365 \mathrm{~nm}$ under a UV lamp, a yellow solution of the complex 10 in the open state turned to the dark green close state complex 1c (Scheme 2). Then, irradiating $1 \mathbf{c}$ at $650 \mathrm{~nm}$ enabled to recover the starting yellow open state 1o. The irradiation time varies, depending on the concentration and the power of the lamp. Note that the closed DTE unit generated two chiral centers at $\alpha$-position of two thiophenes respectively, and because of photochemical electrocyclic reaction rule, conrotatory products were the only products, obtained with the two methyl groups in each side of the DTE plane, thus fixing the chirality of the $\alpha$-carbon as either $(R, R)$ or $(S, S)$. Consequently, molecule 1c can have two diastereomers $(P, R, R)$-1c $($ or $(M, S, S)$-1c) and $(P, S, S)$-1c (or $(M, R, R)$-1c). This photochemical closing process can be monitored by NMR spectroscopy. Indeed, upon UV light irradiation at $365 \mathrm{~nm}$ of a solution of $10\left(5 \times 10^{-2} \mathrm{~mol} \cdot \mathrm{L}^{-1}\right.$ in $\left.\mathrm{CD}_{2} \mathrm{Cl}_{2}\right)$ in an $\mathrm{NMR}$ tube, the conversion to 1c monitored by ${ }^{1} \mathrm{H}$ NMR, revealed that the signals for the two DTE methyl groups at 2.02 and 1.87 ppm were decreasing and 4 signals at 2.19,2.18, 2.16 and $2.15 \mathrm{ppm}$ were increasing with the appearance of the two diastereomers in $1: 1$ ratio, thus showing no stereoselectivity in solution. ${ }^{13}$ In addition, after sufficient irradiation, typically 30 minutes at this concentration, the 10 signals have decreased to less than $2 \%$ (photostationary state, PSS), so that we can consider that 1o can almost fully convert to 1c under $365 \mathrm{~nm}$. Similarly, 1c turned back to 10 with more than $98 \%$ of conversion after sufficient irradiation at $650 \mathrm{~nm}$, although this process took 2 days due to high concentration. This result indicate that this light-triggered switching process occurs with full conversion.

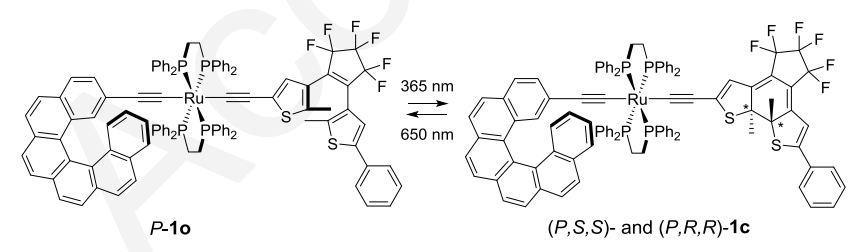

SCHEME 2. Reversible photochromic switching process between 10 and 1c.

The switching process was also investigated by UV-vis spectroscopy, by gradual irradiation at $365 \mathrm{~nm}^{\circ} \mathrm{CH} \mathrm{CH}_{2} \mathrm{Cl}_{2}$ solution $(\mathrm{C} 1 \times$ $10^{-4} \mathrm{~mol} \cdot \mathrm{L}-1$, Figure 2 ). Because of low concentration, the process only needed a few minutes. 


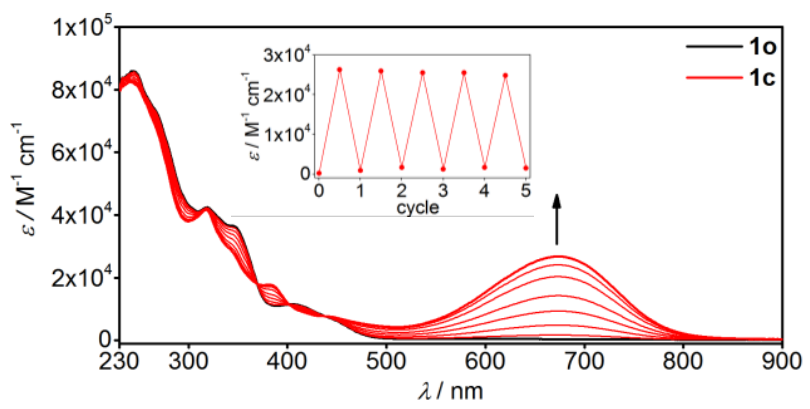

FIGURE 2. Up: Evolution of absorption spectra from 1o to 1c (PSS) by gradual irradiation at $365 \mathrm{~nm}$. Insert: five switching cycles upon alternate irradiation at $365 \mathrm{~nm}$ and $650 \mathrm{~nm}$.

The UV-vis spectrum of 10 in $\mathrm{CH}_{2} \mathrm{Cl}_{2}$ exhibits a high energy band at $245 \mathrm{~nm}$ with $\varepsilon>8 \times 10^{4} \cdot \mathrm{M}^{-1} \cdot \mathrm{cm}^{-1}$, and longer wavelength shoulders at 318 and $347 \mathrm{~nm}$. A band in the visible region at $406 \mathrm{~nm}$ with a shoulder at $445 \mathrm{~nm}$ and tailing down to $500 \mathrm{~nm}$ is also found and most probably corresponds to a MLCT type transition. ${ }^{11 \mathrm{~d}, \mathrm{e}}$ Stepwise irradiation at $365 \mathrm{~nm}$ induced changes of several bands between 300 and $450 \mathrm{~nm}$, with the one at $347 \mathrm{~nm}$ strongly decreasing, and with several isosbestic points, indicating that this process is unimolecular. Furthermore, a strong and broad absorption band at $679 \mathrm{~nm}$ with $\varepsilon$ around $2.7 \times 10^{4} \mathrm{M}^{-1} \cdot \mathrm{cm}^{-1}$ arose due to the $\pi-\pi *$ transition of the closed conjugated DTE unit. Reversibility and repeatability of the process was then studied by irradiating successively the solution at $365 \mathrm{~nm}$ and $650 \mathrm{~nm}$ and monitoring the absorption at $679 \mathrm{~nm}$. A total of 5 cycles were performed with high reversibility (Figure 2 insert). In conclusion, 1o/c shows efficient light-triggered switching activity with the usual good contrast in the visible range ( $\varepsilon$ values from 0 to $2.7 \times 10^{4} \mathrm{M}^{-1} \cdot \mathrm{cm}^{-1}$ at $679 \mathrm{~nm}$ ).

The photoresponsive activity was also followed by ECD spectroscopy. The ECD spectrum of $P$-1o (Figure 3 ) displays three strong negative bands at $247,278 \mathrm{~nm}$ and $303 \mathrm{~nm}\left(\Delta \varepsilon=-178,-81,-27 \mathrm{M}^{-1} \cdot \mathrm{cm}^{-1}\right.$, respectively), strong positive bands at $335 \mathrm{~nm}$ and 351 $\mathrm{nm}\left(\Delta \varepsilon=+88\right.$ and $101 \mathrm{M}^{-1} \cdot \mathrm{cm}^{-1}$, respectively)

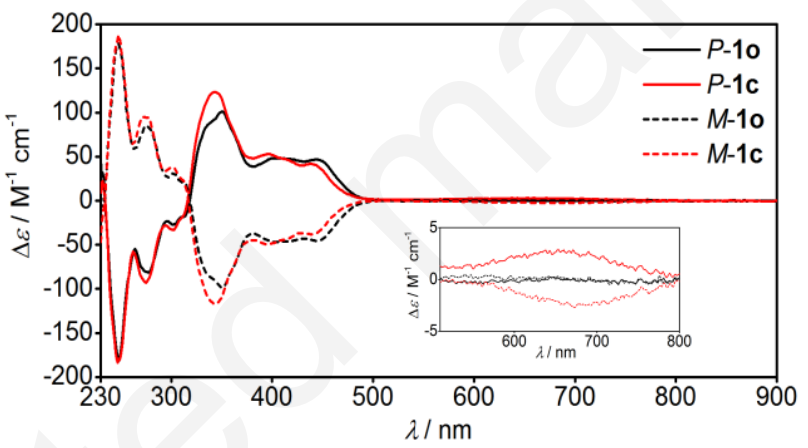

FIGURE 3. ECD spectra of the open state $P$ - and $M-1 \mathrm{o}$, and of the closed state $P$ - and $M-1 \mathrm{c}$ in $\mathrm{CH}_{2} \mathrm{Cl}_{2}\left(C 1 \times 10^{-4} \mathrm{~mol}^{-1} \cdot \mathrm{L}^{-1}\right)$. Insert: zoom between $500-700 \mathrm{~nm}$.

and additional positive bands in the lower energy region at $403 \mathrm{~nm}\left(\Delta \varepsilon=+48 \mathrm{M}^{-1} \cdot \mathrm{cm}^{-1}\right)$ and $445 \mathrm{~nm}\left(\Delta \varepsilon=+46 \mathrm{~L} \cdot \mathrm{mol}^{-1} \cdot \mathrm{cm}^{-1}\right)$ with a tail down to $500 \mathrm{~nm}$. Note that the sign of these two bands agrees well with its starting ligand $P-\mathbf{3}$, thus enabling to confirm the $P$ (+) [and $M-(-)]$ absolute configuration.

Upon irradiation at $365 \mathrm{~nm}$ for a few minutes, $P$-1o could be completely converted into $P$-1c, which showed similar ECD-active bands, but with slight changes in their intensities, the strongest change being found at $343 \mathrm{~nm}$ with an increase from +92 to +122 $\mathrm{M}^{-1} \cdot \mathrm{cm}^{-1}\left(\Delta(\Delta \varepsilon)=30 \mathrm{M}^{-1} \cdot \mathrm{cm}^{-1}\right)$. These results indicate that the ring closure in the DTE unit has an influence on the strong ECDactive bands of the molecule. In addition, the absorption band at $679 \mathrm{~nm}$ appears to be slightly ECD-active, with $\Delta \varepsilon$ small around $+3 \mathrm{~L} \cdot \mathrm{mol}^{-1} \cdot \mathrm{cm}^{-1}$ for $P-1 \mathrm{c}$ enantiomer. Although the signal is small, it corresponds to an induced circular dichroism since the ring closure is not stereoselective, and this illustrates that the chirality of the helicene can influence the DTE response through the ruthenium bridge, thus suggesting a strong electronic communication between each part of the molecule. ${ }^{9,11}$ In summary, these results show that the chiroptical properties of carbon-rich helicenic DTE-Ru conjugate 1o/c can be efficiently tuned by the photochromic DTE ring closure/opening process thus leading to an efficient chiroptical ligh-triggered switching activity.,6

\section{REDOX ACTIVITY OF COMPLEX 10/c}




\section{CYCLIC VOLTAMMETRY}

The redox-triggered switching process was also investigated. First, both the open state $\mathbf{1 o}$ and the closed state 1c were studied by cyclic voltammetry $(\mathrm{CV})$. The $\mathrm{CV}$ measurements were performed in $\mathrm{CH}_{2} \mathrm{Cl}_{2}$ solutions in the dark and under inert atmosphere. $\mathrm{NBu}_{4} \mathrm{PF}_{6}$ was used as the supporting electrolyte $\left(C=0.2 \mathrm{~mol} \cdot \mathrm{L}^{-1}\right)$. The open state 10 shows a reversible oxidation wave with $E_{[1 \mathbf{0}]^{+} / \mathbf{1 0}}^{\circ}=+0.45 \mathrm{~V}\left(v s\right.$. SCE, thereafter), and an irreversible oxidation wave with $E_{[1 \mathbf{0}]^{2+} /[1 \mathbf{0}]^{++}}^{\mathrm{pa}}=+1.31 \mathrm{~V}$ at $0.2 \mathrm{~V} \cdot \mathrm{s}^{-1}$ (Figures $\left.4 \mathrm{a}, \mathrm{b}\right)$, reminiscent of the usual behavior observed for monometallic DTE complexes in their open state. ${ }^{11 \mathrm{f}}$ The close system $1 \mathrm{c}$ shows three

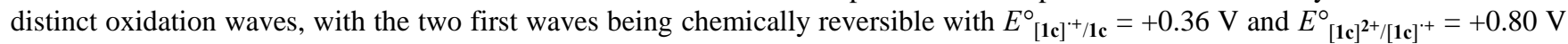
(vs. SCE), whereas the third oxidation wave exhibits partial chemical reversibility at high scanning rate only (Figure 4c-e). The first wave is assigned to the oxidation of the ruthenium carbon-rich system bearing the conjugated closed DTE and helicene units, ${ }^{11 d, e}$ whereas the exact origin of the second and third processes probably involving the conjugated ligands remain unclear so far. Based on these results, it appeared interesting to take advantage of the first reversible oxidation processes of both $\mathbf{1 o}$ and $\mathbf{1 c}$ and to examine their electrochromic activity.
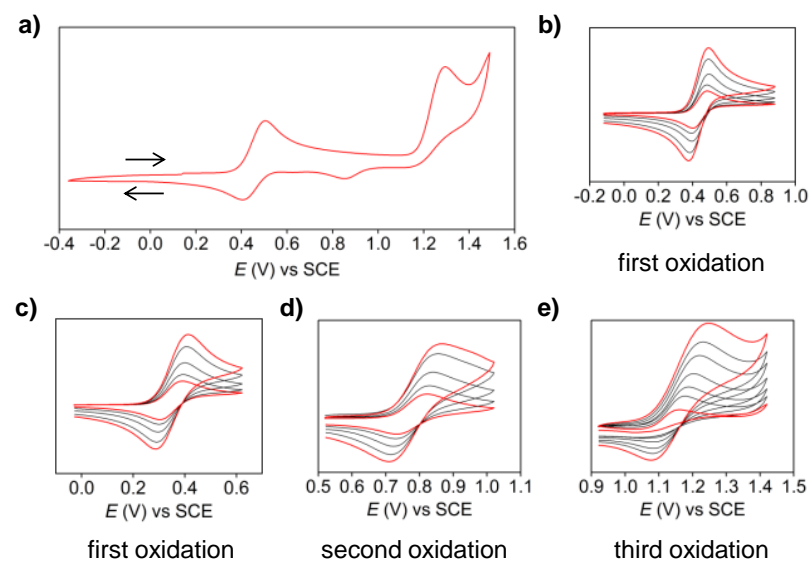

FIGURE 4. a) Full cyclic voltammograms of 10 at scanning rate of $0.2 \mathrm{~V} \cdot \mathrm{s}^{-1}$; b) First oxidation wave of 10 at scanning rates from 0.06 $\mathrm{V} \cdot \mathrm{s}^{-1}$ to $0.6 \mathrm{~V} \cdot \mathrm{s}^{-1}$; c-e) cyclic voltammograms of each oxidation wave of $1 \mathrm{c}$ with different scan-rates: $\mathrm{c}$ ) first oxidation with scan-rates from $0.06 \mathrm{~V} \cdot \mathrm{s}^{-1}$ to $0.6 \mathrm{~V} \cdot \mathrm{s}^{-1}$; d) second oxidation with scan-rates from $0.06 \mathrm{~V} \cdot \mathrm{s}^{-1}$ to $0.6 \mathrm{~V} \cdot \mathrm{s}^{-1}$; e) third oxidation with scan-rates from $0.06 \mathrm{~V} \cdot \mathrm{s}^{-1}$ to $2 \mathrm{~V} \cdot \mathrm{s}^{-1}$.

The first oxidation process of the open form 10 was therefore investigated by spectroelectrochemistry in the UV-Vis-NIR region. The measurements were performed in an optically transparent thin-layer electrochemical (OTTLE) cell at $25{ }^{\circ} \mathrm{C}$ using 1,2 dichloroethane as the solvent $\left(0.2 \mathrm{~mol} \cdot \mathrm{L}^{-1}\right.$ of $\mathrm{NBu}_{4} \mathrm{PF}_{6}$ as the electrolyte and $\mathrm{Ag}$ wire as the pseudo-reference electrode). The evolution of the oxidation process was recorded stepwise by gradual increase of the potential from $-0.2 \mathrm{~V}$ to $+0.6 \mathrm{~V} v s$. Ag wire (Figure 5). The $10 \rightarrow[10]^{++}$process showed several changes in the 250-600 $\mathrm{nm}$ range with the presence of several isosbestic points. In addition, a strong band in the NIR region appeared, centered at $1272 \mathrm{~nm}$ with $\varepsilon$ around $2.3 \times 10^{4} \mathrm{M}^{-1} \cdot \mathrm{cm}^{-1}$. Such NIR feature is typically observed in ruthenium bis(acetylide) oxidized complexes. ${ }^{10}$ The $\mathbf{1 o} \rightarrow[\mathbf{1 0}]^{++}$process was also examined by ECD spectroscopy which revealed significant changes in $P-[\mathbf{1 0}]^{+}$as compared to the starting $P-10$. For instance, the strong positive band at $351 \mathrm{~nm}$ was red-shifted to $360 \mathrm{~nm}$ while the positive ones between 400-500 $\mathrm{nm}$ underwent a strong decrease in their intensities (typically from $\Delta \varepsilon=+47$ to $+17 \mathrm{M}^{-1} \cdot \mathrm{cm}^{-1}$ at $450 \mathrm{~nm}$ i.e. $\left.\Delta(\Delta \varepsilon)=-30 \mathrm{M}^{-1} \cdot \mathrm{cm}^{-1}\right)$. Besides, a new band appeared at $525 \mathrm{~nm}(\Delta \varepsilon=+8$ $\mathrm{M}^{-1} \cdot \mathrm{cm}^{-1}$ ) with a tail down to $560 \mathrm{~nm}$. These results indicate that the redox-triggered switching process is as efficient as the lighttriggered switching process when considering the modulation of the ECD spectra. Note, however, that the NIR band centered on the central metal-carbon-rich part in $[\mathbf{1 0}]^{++}$is not ECD-active. 

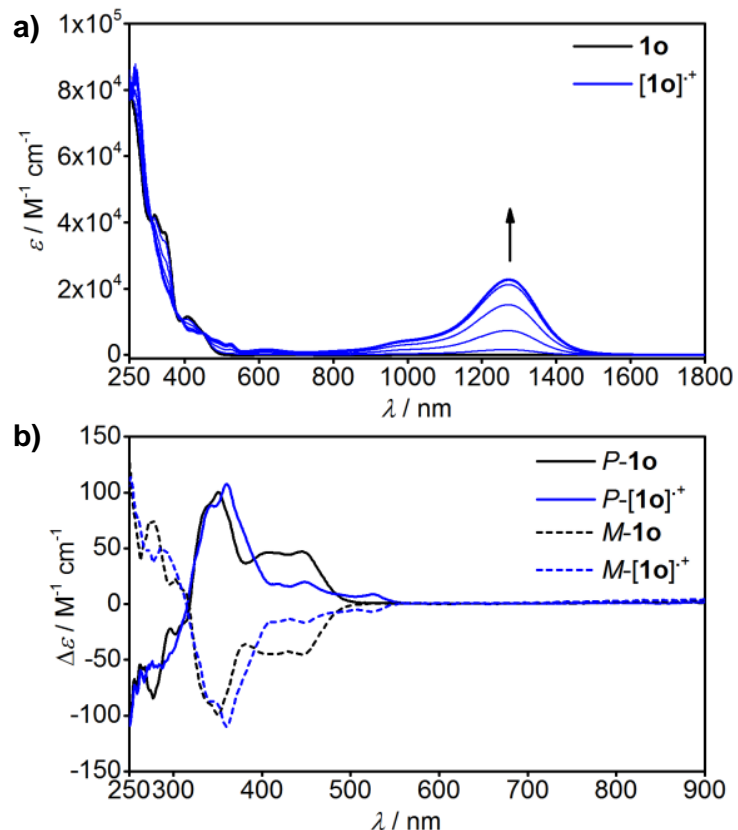

FIGURE 5. a) Evolution of absorption spectra from 1 o to $[1 \mathrm{o}]^{++}$. b) ECD spectra of the open state $P$ - and $M-10$ and of the open oxidized state $P$ - and $M-[10]^{+}$.

The electrochromic activity of 1c was also studied; the first oxidation process was followed upon gradual increase of the potential from $-0.2 \mathrm{~V}$ to $+0.6 \mathrm{~V} v s$. Ag wire (Figure 6). Interestingly, the spectroelectrochemistry revealed an unanticipated result since two stages are appearing in this oxidation process. At the beginning (first stage) of the oxidation, the visible band at $679 \mathrm{~nm}$ regularly decreased with its maximum shifting hypsochromically from $679 \mathrm{~nm}$ to $657 \mathrm{~nm}$. Meanwhile, a new broad band was generated at $965 \mathrm{~nm}$ with tails further than $1800 \mathrm{~nm}$ out of the measurement window. As a result, two distinct isobestic points at $543 \mathrm{~nm}$ and $778 \mathrm{~nm}$ were observed. A strong positive current was detected, indicating that there was an oxidation process occurring during these observations. Then, (second stage), a broad signal peak at $1272 \mathrm{~nm}$ started to be generated, while the signal at $965 \mathrm{~nm}$ started to decrease; at this stage, no current production was detected anymore. Finally, this process stopped when the band at $1272 \mathrm{~nm}$ reached its maximum around $2 \times 10^{4} \mathrm{M}^{-1} \cdot \mathrm{cm}^{-1}$, and the bands at $657 \mathrm{~nm}$ and $964 \mathrm{~nm}$ almost disappeared. From the changes of spectra and current responses, one can conclude that the second step was not directly induced by electrochemical oxidation. Besides, the final spectrum was found to be very similar to the spectrum of $[\mathbf{1 0}]^{++}$with the same absorption band at $1272 \mathrm{~nm}$. Thus, these observations indicate that the two steps should correspond to the oxidation step that generates [1c] ${ }^{+}$from 1c with two signals at $657 \mathrm{~nm}$ and $964 \mathrm{~nm}$, followed by the ring opening isomerization of [1c] ${ }^{+}$to $[\mathbf{1 0}]^{+}$. As 1c is easier to oxidize than 1o, each produced $[\mathbf{1 0}]^{+}$species can oxidize another molecule of $1 \mathbf{c}$ to lead to another ring opening and so on. This process thus is an electrocatalytic process, ${ }^{12}$ observed for the first time with ruthenium complex/DTE adducts. Indeed, a final reduction enabled to go back to the open form 10 while another irradiation of 10 at $365 \mathrm{~nm}$ regenerated the closed form 1c again. All these steps (1 to 4$)$ are summarized on Figure 7.

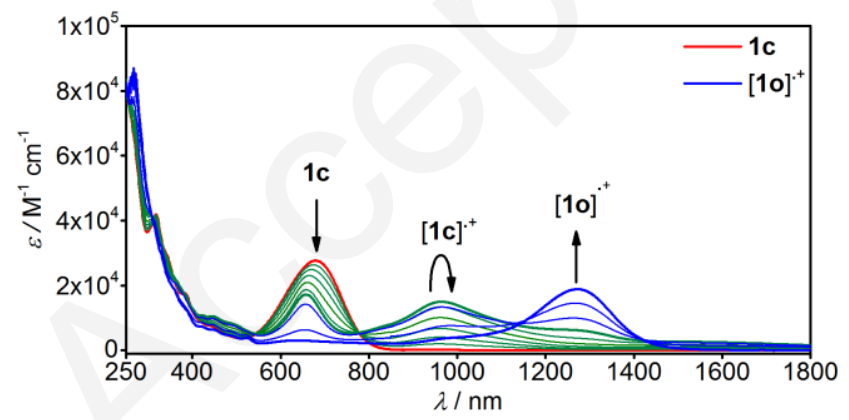

FIGURE 6. Evolution of absorption spectra during the oxidation process $1 \mathrm{c} \rightarrow[1 \mathrm{c}]^{++} \rightarrow[1 \mathrm{o}]^{{ }^{+}}$.

\section{"NOR" LOGIC GATE}

As a result, a three-state cycling process (Figure 8a) can be performed starting from 1o: $i$ ) irradiation at $365 \mathrm{~nm}$ generates $\mathbf{1 c}$; $i$ ) oxidizing 1c forms $[\mathbf{1 0}]^{++}$at $+0.6 \mathrm{~V}$ (vs. Ag wire); iii) reducing [10] ${ }^{++}$leads back to 10 at $-0.4 \mathrm{~V}$ (vs. Ag wire). A total of 5 full cycles could be performed, and by reading $\varepsilon$ values at $679 \mathrm{~nm}$ and at $1272 \mathrm{~nm}$. It was found that at $679 \mathrm{~nm}$ the signal shows 
$\mathrm{OFF} \rightarrow \mathrm{ON} \rightarrow \mathrm{OFF}$, while at $1272 \mathrm{~nm}$ the signal shows $\mathrm{OFF} \rightarrow \mathrm{OFF} \rightarrow \mathrm{ON}$ responses (Figure 8b). Note that after 5 cycles around $50 \%$ of degradation in our conditions was observed, probably due to partial degradation of the oxidized radical species during the process. Besides, based on this unique photochromic and electrochromic property, this molecule can be treated as an optical logic gate at $679 \mathrm{~nm} .{ }^{14}$ One may define that the open state 10 with low absorption at $679 \mathrm{~nm}$ as " 0 ", and closed state 1c with high absorption at $679 \mathrm{~nm}$ as "1". The output can be measured by UV-vis absorption. Starting from 1c, two inputs can be applied: irradiation at 650 $\mathrm{nm}(\mathrm{h} v)$ and external potential at $+0.6 \mathrm{~V}$, then $-0.4 \mathrm{~V} v s$. Ag wire (E). These two inputs can be defined as either " 0 " and " 1 ". Either irradiation $(1,0)$ or external potential $(0,1)$ or together $(1,1)$ can trigger the ring opening reaction of $\mathbf{1 c}$ and form the low absorption species 10 (output 0 ). So, we can treat this process as an "NOR" logic gate (Figure 8c). ${ }^{14}$
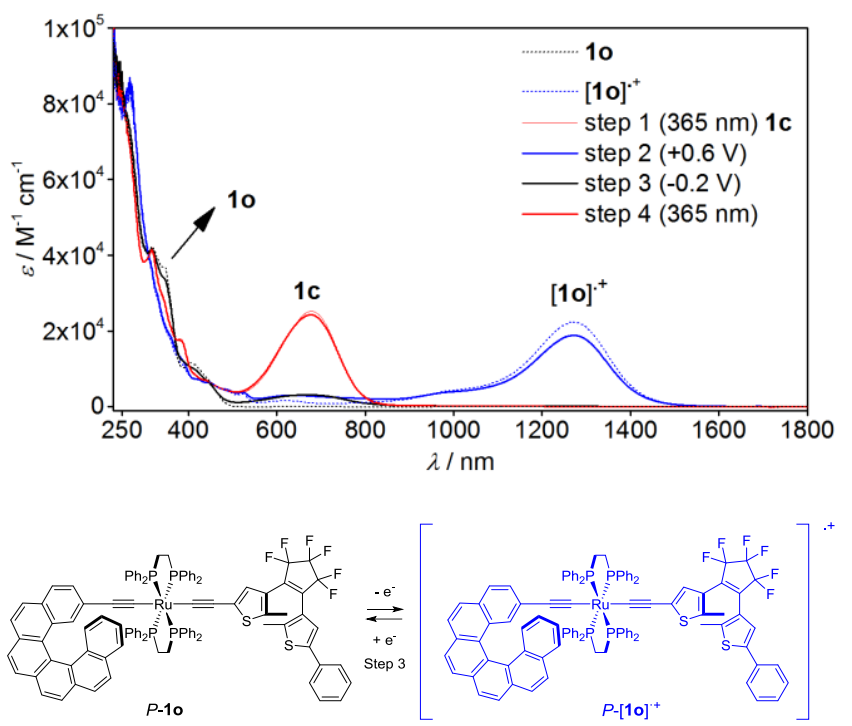

$650 \mathrm{~nm} \uparrow \mid 365 \mathrm{~nm}$ Steps 1,4

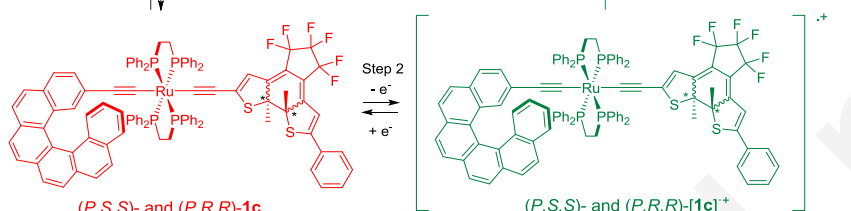

$(P, S, S)$ - and $(P, R, R)-1 \mathrm{c}$

$(P, S, S)$ - and $(P, R, R)-[1 \mathrm{c}]^{+}$

FIGURE 7. The photochromic and electrochromic steps of cycle $1 \mathrm{o} \rightarrow 1 \mathrm{c} \rightarrow[1 \mathrm{c}]^{++}($reactive $) \rightarrow[1 \mathrm{o}]^{++} \rightarrow 1 \mathrm{o}$.

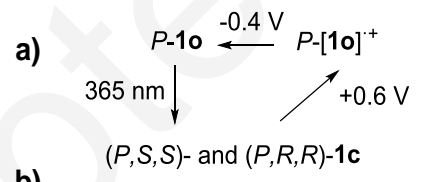

b)

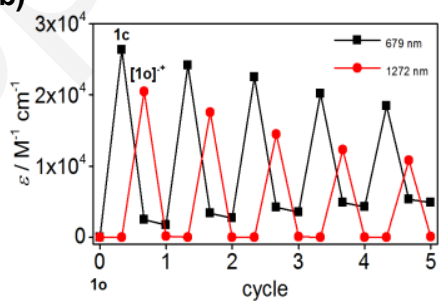

c)

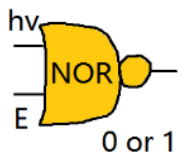

\begin{tabular}{c|cccc}
\hline $\mathrm{h} v$ & 0 & 0 & 1 & 1 \\
$\mathrm{E}$ & 0 & 1 & 0 & 1 \\
\hline Output & 1 & 0 & 0 & 0 \\
\hline
\end{tabular}

FIGURE 8. a) Three-state cycle obtained from the 1o/1c system upon light and redox stimuli; b) Five switching cycles between 1o $\rightarrow 1 \mathrm{c}$ $\rightarrow[1 \mathrm{o}]^{++}$at $679 \mathrm{~nm}$ (black) and $\left.1272 \mathrm{~nm}(\mathrm{red}) ; \mathrm{c}\right)$ symbol and truth table of the "NOR" logic gate.

In summary, the mono-helicenic-ruthenium DTE conjugate 1o/c undergoes easy redox-triggered cycloreversion, i.e. ring opening of the closed form 1c upon oxidation. In comparison, systems from the literature ${ }^{11 \mathrm{c}}$ display one DTE unit and two -Ru- arylethynyle- centers and all show redox-triggered ring closure of the DTE units upon oxidation, a particular case that we also applied to the chiroptical system.

\section{PHOTOCHEMICAL SWITCHING ACTIVITY OF 20}


Complex 20 displayed similar photochromic behavior as $\mathbf{1 0}$ and could be transformed to the closed state 2c upon irradiation at 365 $\mathrm{nm}$ and recovered back to the open state $2 \mathbf{o}$ by irradiation at $650 \mathrm{~nm}$. Like 1c, $2 \mathbf{c}$ was also generated as a pair of diastereoisomers due to the newly formed chiral center at $\alpha$-positions of the two thiophenes. The conrotatory ring closing reaction can generate both $(R, R)$ and $(S, S)$ configurations and thus generate a pair of diastereomers $(P, P, R, R)$ - and $(P, P, S, S)$-2c when starting from the enantiopure $(P, P)$-2o (Scheme 3). The photochemical process was followed by UV-vis spectroscopy. Complex 2o shows similar UV-vis spectrum as 10 but with stronger intensity, and displayed a strong band at $244 \mathrm{~nm}\left(\varepsilon>1.4 \times 10^{5} \mathrm{M}^{-1} \cdot \mathrm{cm}^{-1}\right)$, two moderate ones at 323 and $349 \mathrm{~nm}\left(\varepsilon \sim 7 \times 10^{4} \mathrm{M}^{-1} \cdot \mathrm{cm}^{-1}\right)$ and another band in the visible region at $406 \mathrm{~nm}$ with a shoulder at $450 \mathrm{~nm}$ and tailing down to $500 \mathrm{~nm}$ (MLCT, $\varepsilon \sim 1.4 \times 10^{4} \mathrm{M}^{-1} \cdot \mathrm{cm}^{-1}$ at $450 \mathrm{~nm}$ ). Upon step-wise irradiation to $2 \mathrm{c}$, the yellow solution turned to very deep dark green. Several isobestic points were observed in the UV-vis spectrum, with a strong decrease of the signal at $349 \mathrm{~nm}$ and two new bands appearing at longer wavelengths at 665 and $720 \mathrm{~nm}\left(\varepsilon 3.8 \times 10^{4} \mathrm{M}^{-1} \cdot \mathrm{cm}^{-1}\right)$ due to the greater $\pi$-extended conjugation of the closed DTE unit. The presence of several transitions in this range is typical of DTE bearing two ruthenium bis(acetylide) moieties displaying several conformers. ${ }^{1 \mathrm{e}}$ This process was also studied by NMR spectroscopy and full conversion was verified together with the formation of two diastereoisomers in a 1:1 ratio as demonstrated for instance by ${ }^{1} \mathrm{H}$ and ${ }^{19} \mathrm{~F}$ NMR spectroscopies (see SI).

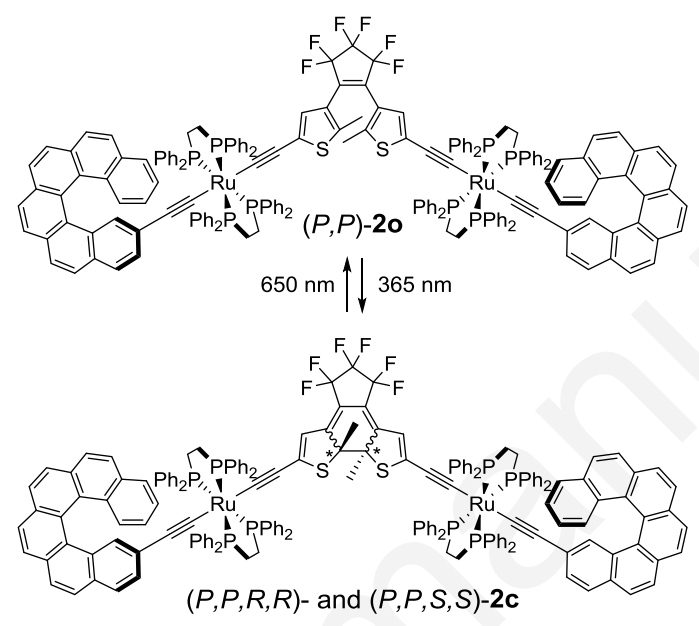

SCHEME 3. Photochromic switching between 20 and $2 \mathrm{c}((P, P)$ enantiomers).

$(P, P)$-2o shows quite similar ECD spectrum as $P$-1o, but with intensities twice as large for most of the signals indicating that these ECD signals are mainly contributing from the helicene-ruthenium parts with almost no electronic communication between these two parts through the open DTE bridge. When 20 is transformed into 2c upon irradiation at $365 \mathrm{~nm}$, the ECD-active band centered at $350 \mathrm{~nm}$ increased while the band at $445 \mathrm{~nm}$ decreased. Notably, a weak band around $679 \mathrm{~nm}$ with a $\Delta \varepsilon \mathrm{value} \mathrm{of}+6 \mathrm{~L} \cdot \mathrm{mol}^{-1} \cdot \mathrm{cm}^{-1}$ was also observed and indicated an induced ECD response from the helicene parts to the DTE chromophore. 

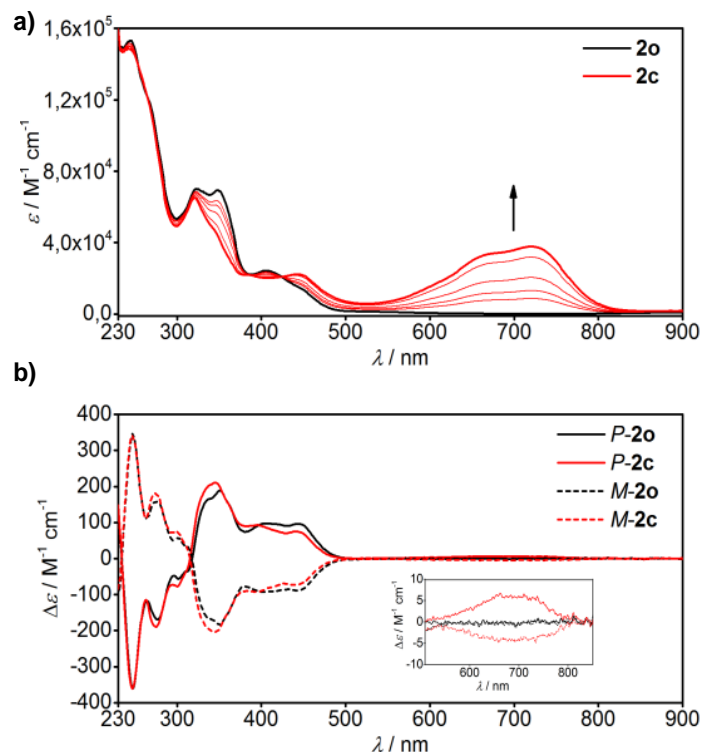

FIGURE 9. a) Evolution of absorption spectra from 2o to $2 \mathrm{c}$ by gradual irradiation at $365 \mathrm{~nm}$. b) ECD spectra of the open neutral state $(P, P)-2 \mathrm{o},(M, M)-2 \mathrm{o}$, the closed neutral state $(P, P, R, R)$ - and $(P, P, S, S)-2 \mathrm{c}$ and $(M, M, S, S)$ - and $(M, M, R, R)-2 \mathrm{c}$. Insert: zoom between $500-850$ nm.

\section{REDOX ACTIVITY OF COMPLEX 2o/c}

\section{CYCLIC VOLTAMMETRY}

The cyclic voltammetry for both 20 and $2 \mathrm{c}$ was first examined. The $\mathrm{CV}$ measurements were performed in $\mathrm{CH}_{2} \mathrm{Cl}_{2}$ solution in the dark and under inert atmosphere $\left(0.2 \mathrm{~mol} \cdot \mathrm{L}^{-1} \mathrm{NBu}_{4} \mathrm{PF}_{6}\right.$ as the supporting electrolyte). The open state 20 presents an almost reversible broad redox system at $0.43 \mathrm{~V} v s$. SCE which is composed of two close one-electron oxidation processes corresponding to the two electronically independent ruthenium carbon rich systems and leading to $[\mathbf{2 o}]^{2+}$ as previously observed for parents complexes. ${ }^{11 \mathrm{~d}, \mathrm{e}}$ Notably, both the DTE unit and the helicenes ligands are non-innocent ligands and contribute to the oxidation process. For the closed state $\mathbf{2 c}$, two reversible monoelectronic oxidation waves with close potential values were found with $E^{\circ} \mathbf{c}^{-+} / \mathbf{2 c}=+0.10 \mathrm{~V}$ and $E^{\circ}{ }_{2 \mathbf{c}^{2+} / 2 \mathbf{c}^{++}}=+0.21 \mathrm{~V}$ (see SI). This result shows that the two halves of the complex are no longer independent because of the electronic communication through the closed conjugated DTE bridge. ${ }^{9}$

\section{ELECTROCHROMIC ACTIVITY}

Spectroelectrochemical studies in the UV-vis-NIR region was then performed of the open form 2o in 1,2-dichloroethane with $\mathrm{NBu}_{4} \mathrm{PF}_{6}$ as the supporting electrolyte in the OTTLE cell well-protected from air and light. The evolution curves of the twoelectrons oxidation process $\mathbf{2 0} \rightarrow[\mathbf{2 0}]^{2+}$ were recorded by stepwise increase of potential from $-0.6 \mathrm{~V}$ to $+0.7 \mathrm{~V}$ ( $\mathrm{vs}$. Ag wire pseudo-reference electrode). The results indicated the expected multi-step process (Figure 10): a strong and broad new band appeared between 600 and $1100 \mathrm{~nm}$, centered at $825 \mathrm{~nm}$ with $\varepsilon=2.2 \times 10^{4} \mathrm{~L} \cdot \mathrm{mol}^{-1} \cdot \mathrm{cm}^{-1}$, while a band in the low energy domain at $1268 \mathrm{~nm}$ firstly appeared and then decreased, indicating that isomerization occurred. ${ }^{11 \mathrm{~d}, \mathrm{e}}$ Indeed, reduction of this oxidized species by applying a potential of $-0.6 \mathrm{~V}$, no longer yielded $\mathbf{2 0}$, but $\mathbf{2 c}$ with almost full conversion, as illustrated by the strong bands at 665 and 720 $\mathrm{nm}$ characteristic of $\mathbf{2 c}$ in the UV-visible spectrum. Then, we could observe that further photo irradiation at $650 \mathrm{~nm}$ fully regenerated complex $\mathbf{2 0}$. 


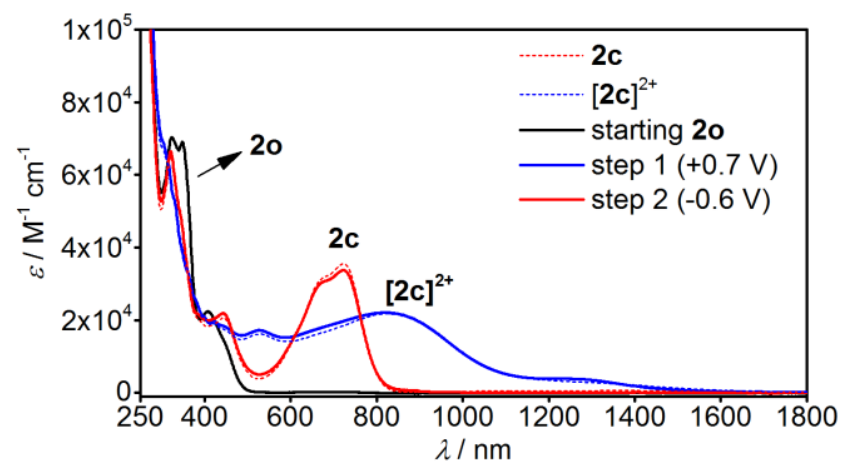

FIGURE 10. The electrochromic steps of cycle $2 \mathrm{o} \rightarrow[2 \mathrm{o}]^{2+}($ not observed $) \rightarrow[2 \mathrm{c}]^{2+} \rightarrow 2 \mathrm{c}$.

To further explore the isomerization from $[\mathbf{2 o}]^{2+}$ to $[\mathbf{2 c}]^{2+}$, we also studied the electrochromic property of the closed state $\mathbf{2 c}$. Complex $\mathbf{2 c}$ shows progressive transformation to the first oxidized state $[\mathbf{2 c}]^{+}$upon oxidation (Figure 11a), then to the second oxidized state $[\mathbf{2 c}]^{2+}$ (Figure 11c) with several identical isosbestic points. In the first oxidation of $\mathbf{2 c}$, the strong bands at 665 and $720 \mathrm{~nm}$ decreased and two new strong bands appeared at 1125 and $1355 \mathrm{~nm}$ with a tail longer than $1800 \mathrm{~nm}$. In the second oxidation process, these two bands decreased, and a new band centered at $825 \mathrm{~nm}$ formed, indicating the formation of [2c] ${ }^{2+}$. This spectrum is very similar to the one coming from the oxidation of $\mathbf{2 0}$. Furthermore, the reduction process of $[\mathbf{2 c}]^{2+}$ leads back to $\mathbf{2 c}$. From these results, one can conclude that the redox process from $\mathbf{2 c}$ to $[\mathbf{2 c}]^{2+}$ is reversible with an intermediate $[2 \mathbf{c}]^{++}$, while the redox process of 20 is irreversible with the isomerization in the oxidation process from $[\mathbf{2 o}]^{2+}$ to $[\mathbf{2 c}]^{2+}$. These result are in line with previous observations from parent complexes. ${ }^{11 \mathrm{~d}, \mathrm{e}}$

Reversible evolution of $\mathbf{2 c} \rightarrow[\mathbf{2 c}]^{++} \rightarrow[\mathbf{2 c}]^{2+}$ was also monitored by ECD spectroelectrochemistry (Figures $\left.11 \mathrm{~b}, \mathrm{~d}, \mathrm{e}, \mathrm{f}\right)$. For $(P, P)-\mathbf{2 c}$ $\rightarrow(P, P)-[2 \mathbf{c}]^{++}$, large changes were found between 300 to $500 \mathrm{~nm}$ with several isosbestic points. The most interesting change occurred in the lower energy region. Indeed, $(P, P)$-2c showed an ECD-active band at $679 \mathrm{~nm}$ with $\Delta \varepsilon=+6 \mathrm{~L} \cdot \mathrm{mol}^{-1} \cdot \mathrm{cm}^{-1}$. Upon oxidation to $(P, P)-[\mathbf{2 c}]^{++}$, this band shifted to $700 \mathrm{~nm}$ and decreased in intensity to $+4 \mathrm{~L} \cdot \mathrm{mol}^{-1} \cdot \mathrm{cm}^{-1}$ (Figure $11 \mathrm{e}$ ). Upon further oxidation to $(P, P)-[2 \mathrm{c}]^{2+}$, this band became bisignate with positive sign at $625 \mathrm{~nm}\left(\Delta \varepsilon=+8 \mathrm{~L} \cdot \mathrm{mol}^{-1} \cdot \mathrm{cm}^{-1}\right)$ and negative sign at $800 \mathrm{~nm}$ $\left(\Delta \varepsilon=-6 \mathrm{~L} \cdot \mathrm{mol}^{-1} \cdot \mathrm{cm}^{-1}\right)$ (Figure 11f).

a)

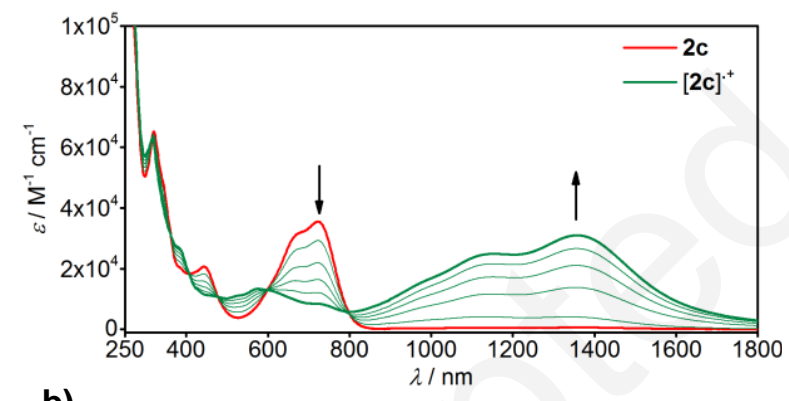

b)

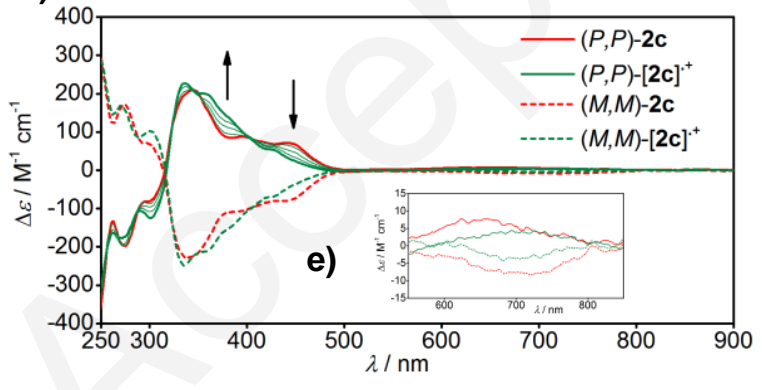

C)
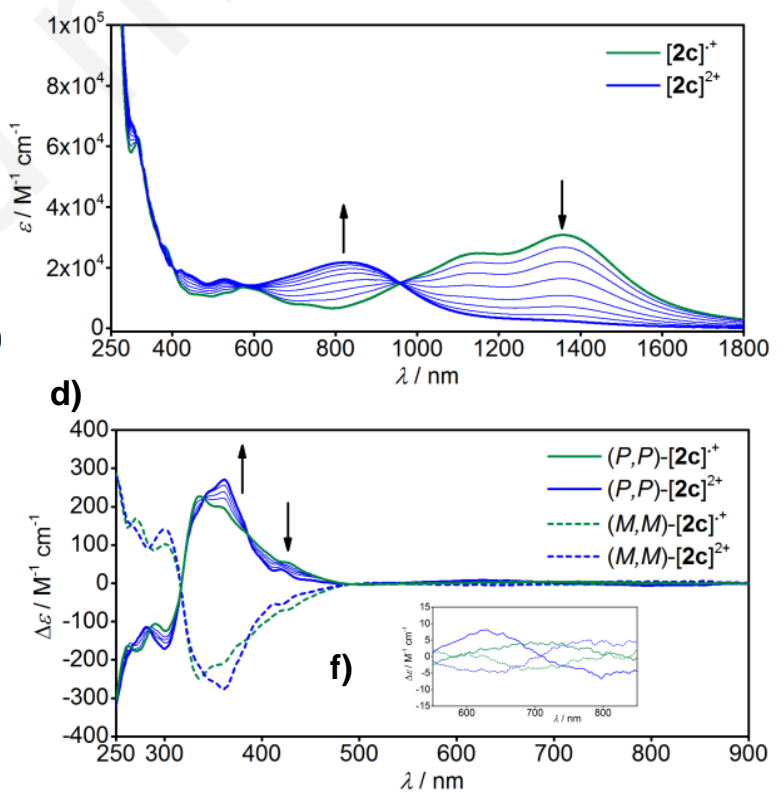

FIGURE 11. Absorption changes in the UV-vis-NIR range observed upon oxidative transformations $2 \mathrm{c} \rightarrow[2 \mathrm{c}]^{++}(11 \mathrm{a})$ and $[2 \mathrm{c}]^{++} \rightarrow[2 \mathrm{c}]^{2+}$ (11c) and their corresponding spectroelectrochemical ECD spectra of the $(P, P)$ and $(M, M)$ enantiomers $(11 \mathrm{~b}, \mathrm{~d}, \mathrm{e}, \mathrm{f})$.

Finally, the oxidation process of $\mathbf{2 0}$ was also examined, and, as expected, the oxidation ended-up with the spectrum of [2c $]^{2+}$, which is another proof of the isomerization from $[20]^{2+}$ to $[2 \mathbf{c}]^{2+}$ (see Figure 12). 


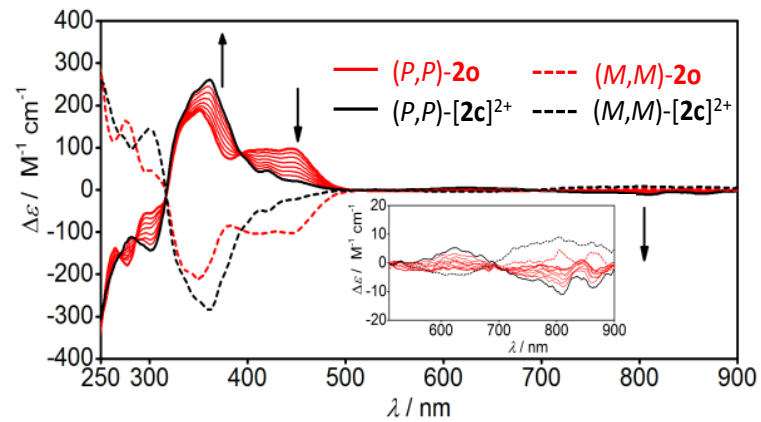

Figure 12. ECD spectra of the open neutral state $(P, P)$ - and $(M, M)-20$ and their evolution upon oxidation to $(P, P)$ - and $(M, M)-[2 \mathrm{c}]^{2+}$. Insert: zoom between 500-900 $\mathrm{nm}$.

\section{"OR" LOGIC GATE}

Based on its photochromic and electrochromic properties, complex 2o,c can also be used as a logic gate. ${ }^{14}$ For example, we can use the absorption $(\varepsilon)$ or the circular dichroism $(\Delta \varepsilon)$ of this molecule at $679 \mathrm{~nm}$ as outputs. The absence of absorption nor CD signal defines " 0 ", a high absorption or CD signal, defines " 1 ". Two inputs can be also defined: irradiation at $365 \mathrm{~nm}$ corresponds to "1" in the photochemical process, otherwise " 0 " corresponds to no irradiation. External redox potential of $+0.7 \mathrm{~V}$ then of $-0.6 \mathrm{~V} v s$. Ag wire corresponds to " 1 " in E, otherwise " 0 " corresponds to the absence of redox stimulus. In this logic gate, when there is no irradiation nor potential $(0,0)$, the open state 20 can keep its open form, so the output is still " 0 ". However, when there is either irradiation $(1,0)$ or the external potential $(0,1)$ or both $(1,1)$, the open state $\mathbf{2 o}$ will transform to the closed state $\mathbf{2 c}$, the output will then be " 1 ". As a result, the system can be described as an "OR" logic gate (Figure 13). ${ }^{14}$

\section{a)}

$(P, P)-20^{650 \mathrm{~nm}}$

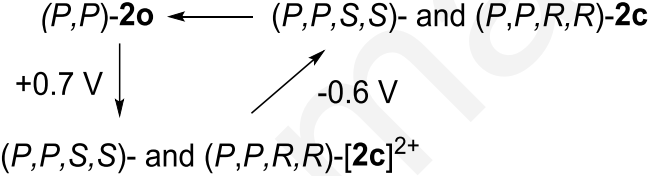

b)

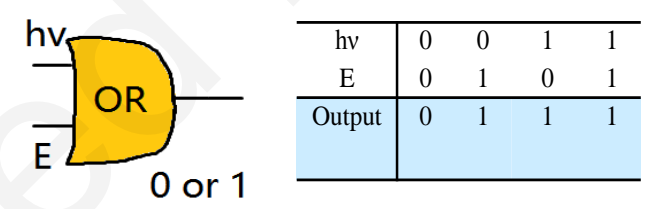

Figure 13. a) Three-state cycle obtained from the $2 \mathrm{o} / 2 \mathrm{c}$ system upon light and redox stimuli; b) The symbol of "OR" logic gate and its truth table.

\section{CONCLUSION}

In conclusion, we have synthesized enantiomerically enriched mono- and bis-([6]helicene- $\left.\equiv-\operatorname{Ru}(\mathrm{dppe})_{2}-\equiv\right)$-DTE complexes 1o,c and 2o,c. Both the photochromic and electrochromic properties were studied and attractive isomerization processes were observed, i.e. ring opening from closed oxidized state to open oxidized in the case of the mono-substituted helicene-alkynyl-Ru complex 1o,c, and ring closure from open oxidized state to closed oxidized in the case of the bis-substituted helicene-alkynyl-Ru complex 2o,c. These properties make these complexes new types of molecular "NOR"/"OR" logic gates with output being both absorption or the circular dichroism signal. These systems also appeared as new types of light- and redox-triggered organometallic chiroptical switches. ${ }^{6,15}$

\section{ASSOCIATED CONTENT}

\section{Supporting Information}


The Supporting Information is available free of charge on the ACS Publications website: experimental procedures for 1o,c and 2o,c, NMR and X-ray data. Cif and checkcif files of 10 .

\section{AUTHOR INFORMATION}

\section{Corresponding Author}

Email: stephane.rigaut@univ-rennes1.fr, jeanne.crassous@univ-rennes1.fr

\section{ORCID}

Jeanne Crassous: 0000-0002-4037-6067

Stéphane Rigaut: 0000-0001-7001-9039

Lucie Norel : 0000-0001-6654-1211

\section{Notes}

The authors declare no competing financial interest.

\section{ACKNOWLEDGMENT}

We thank the Ministère de l'Education Nationale, de la Recherche et de la Technologie, the Centre National de la Recherche Scientifique (CNRS), University of Rennes 1, and the ANR (12-BS07-0004-METALHEL-01).

\section{REFERENCES}

(1) a) Martin, R. H. Angew. Chem., Int. Ed. 1974, 13, 649-660; b) Katz, T. J. Angew. Chem. Int. Ed. 2000, 39, 1921-1923; c) Urbano, A. Angew. Chem. Int. Ed. 2003, 42, 3986-3989; d) Rajca, A.; Miyasaka, M. in: Müller, T. J. J.; Bunz U.H. F. (Eds.), Functional Organic Materials, Wiley-VCH Verlag GmbH \& Co. KGaA, 2007, p. 547; e) Dumitrascu, F.; Dumitrescu, D. G.; Aron, I. Arkivoc 2010, 1, 1-32; f) Stara, I. G.; Stary, I. in: Siegel, J. S.; Tobe Y. (Eds.), Science of Synthesis, Thieme, Stuttgart, 2010, 45, p. 885; g) Shen, Y.; Chen, C. -F. Chem. Rev. 2011, 112, 1463-1535; h) Gingras, M. Chem. Soc. Rev. 2013, 42, 968-1006; i) Saleh, N.; Shen, C.; Crassous, J. Chem. Sci. 2014, 5, 36803694; j) Bosson, J.; Gouin, J.; Lacour, J. Chem. Soc. Rev. 2014, 43, 2824-2840; k) Aillard, P.; Voituriez, A.; Marinetti, A. Dalton Trans. 2014, 43, 15263-15278.

(2) a) Furche, F.; Ahlrichs, R.; Wachsmann, C.; Weber, E.; Sobanski, A.; Vögtle, F.; Grimme, S. J. Am. Chem. Soc. 2000, 122, 1717-1724; b) Autschbach, J. Chirality 2009, 21, E116.

(3) a) Riehl, J. P.; Muller, G. in: N. Berova, P. L. Polavarapu, K. Nakanishi, R. W. Woody (Eds.), Comprehensive Chiroptical Spectroscopy, vol. 1, John Wiley \& Sons, Inc., 2012, p. 65; b) Maeda, H.; Bando, Y. Pure Appl. Chem. 2013, 85, 1967-1978; c) Sanchez-Carnerero, E. M.; Agarrabeitia, A. R.; Moreno, F.; Maroto, B. L.; Muller, G.; Ortiz, M. J.; de la Moya, S. Chem. Eur. J. 2015, 21, 1-14

(4) a) Amabilino D. (Ed.), Chirality at the Nanoscale, Nanoparticles, Surfaces, Materials and more, Wiley-VCH, 2009; b) B. L. Feringa, W.R. Browne, Molecular Switches, 2nd edition, Wiley-VCH, 2011; c) V. Balzani, A. Credi, M. Venturi (Eds.), Molecular Devices and Machines. Concepts and Perspectives for the Nanoworld, Wiley-VCH, Weinheim, 2008.

(5) a) Canary, J. W.; Mortezaei, S.; Liang, J. Coord. Chem. Rev. 2010, 254, 2249-2266; b) Miyake, H.; Tsukube, H. Chem. Soc. Rev. 2012, 41, 6977-6991; c) Crassous, J. Chem. Comm. 2012, 48, 9687-9695; d) Dai, Z.; Lee, J.; Zhang, W. Molecules, 2012, 17, $1247-1277$.

(6) a) Anger, E.; Srebro, M.; Vanthuyne, N.; Toupet, L.; Rigaut, S.; Roussel, C.; Autschbach, J.; Crassous, J.; Réau, R. J. Am. Chem. Soc. 2012, 134, 15628-15631; b) Biet, T.; Fihey, A.; Cauchy, T.; Vanthuyne, N.; Roussel, C.; Crassous J., Avarvari, N. Chem. Eur. J. 2013, 19, 13160-13167; c) Anger, E.; Srebro, M.; Vanthuyne, N.; Roussel, C.; Toupet, L.; Autschbach, J.; Réau, R.; Crassous. J. Chem. Comm. 2014, 50, 2854; c) Schweinfurth, D.; Zalibera, M.; Kathan, M.; Shen, C.; Mazzolini, M.; Trapp, N.; Crassous, J.; Gescheidt, G.; Diederich, F. J. Am. Chem. Soc. 2014, 136, 13045-13052; d) Srebro, M.; Anger, E.; Moore, II, B.; Vanthuyne, N.; Roussel, C.; Réau, R.; Autschbach, J.; Crassous, J. Chem. Eur. J. 2015, 21, 17100-17115; d) Saleh, N.; Moore, II, B.; Srebro, M.; Vanthuyne, N.; Toupet, L.; Williams, J. A. G.; Roussel, C.; Deol, K. K.; Muller, G.; Autschbach, J.; Crassous, J. Chem. Eur. J. 2015, 21, 1673-1681; e) Shen, C.; Loas, G.; Srebro-Hooper, M.; Vanthuyne, N.; Toupet, L.; Cador, O.; Paul, F.; López Navarrete, J. T.; Ramírez, F. J.; Nieto-Ortega, B.; Casado, J.; Autschbach, J.; Vallet, M.; J. Crassous, Angew. Chem. Int. Ed. 2016, 55, 8062-8066; f) Isla, H.; Srebro-Hooper,' M.; Jean, M.; Vanthuyne, N.; Roisnel, T.; Lunkley, J. L.; Muller, G.; Williams, J. A. G.; Autschbach, J.; Crassous, J. Chem. Comm. 2016, 52, 5932-5935; g) For a review on helicenebased chiroptical switches see: Isla, H.; Crassous, J.Comptes Rendus Chimie 2016, 19, 39-49.

(7) a) Irie, M. Chem. Rev. 2000, 100, 1685-1716; b) Irie, M.; Fukaminato, T.; Matsuda, K.; Kobatake, S. Chem. Rev. 2014, 114,12174 12277.

(8) a) Dinescu, L.; Wang, Z. Y. Chem. Commun. 1999, 2497-2498; b) Norsten, T. B.; Peters, A.; McDonald, R.; Wang, M.; Branda, N. R. J. Am. Chem. Soc. 2001, 123, 7447-7448; c) Wigglesworth, T. J.; Sud, D.; Norsten, T. B.; Lekhi, V. S.; Branda, N. R. J. Am. Chem. Soc. 2005, 
127, 7272-7273; d) Okuyama, T.; Tani, Y.; Miyake, K.; Yokoyama, Y. J. Org. Chem. 2007, 72, 1634-1638; e) Tani, Y.; Ubukata, T.; Yokoyama, Y.; Yokoyama, Y. J. Org. Chem. 2007, 72, 1639-1644.

(9) (a) Aguirre-Etcheverry, P.; O Hare, D. Chem. Rev. 2010, 110, 4839-4864; b) Costuas, K.; Rigaut, S. Dalton T. 2011, 40, 5643-5658; c) Low, P. J. Coord. Chem. Rev. 2013, 257, 1507-1532.

(10) a) Di Piazza, E.; Norel, L.; Costuas, K.; Bourdolle, A.; Maury, O.; Rigaut S. J. Am. Chem. Soc. 2011, 133, 6174-6176; b) Norel, L; Di Piazza, E.; Feng, M. A.; Vacher, A.; He, X.; Roisnel, T.; Maury, O.; Rigaut, S. Organometallics 2014, 33, 4824-4835; c) Samoc, M.; Gauthier, N.; Cifuentes, M. P.; Paul, F.; Lapinte C.; Humphrey, M. G. Angew. Chem. Int. Ed., 2006, 45, 7376-7379; d) Norel, L.; Min, F.; Bernot, K.; Roisnel, T.; Guizouarn, T.; Costuas, K.; Rigaut, S. Inorg. Chem. 2014, 53, 2361-2363; e) Mahapatro, A. K.; Ying, J.; Ren, T. ;and Janes, D. B. Nano Lett., 2008, 8, 2131-2136; f) Burgun, A.; Gendron, F.; Sumby, C. J.; Roisnel, T.; Cador, O.; Costuas, K.; Halet, J.-F.; Bruce, M. I.; Lapinte, C. Organometallics 2014, 33, 2613-2627; g) Di Piazza, E.; Merhi, A.; Norel, L.; Choua, S.; Turek, P.; Rigaut, S. Inorg. Chem. 2015, $54,6347-6355$.

(11) a) Motoyama, K.; Koike, T.; Akita, M. Chem. Commun. 2008, 5812; b) Tanaka, Y.; Ishisaka, T.; Inagaki, A.; Koike, T.; Lapinte, C.; Akita, M. Chem. Eur. J. 2010, 16, 4762. c) Tanake, Y.; Inagaki, A.; Akita, M. Chem. Commun. 2007, 1169-1171; d) Liu, Y.; Lagrost, C.; Costuas, K.; Tchouar, N.; Bozec, H. L.; Rigaut, S. Chem. Commun. 2008, 6117-6119; d) Hervault, Y.; Ndiaye, C. M.; Norel, L.; Lagrost, C.; Rigaut, S. Org. Lett. 2012, 14, 4454-4457; e) Liu, Y.; Ndiaye, C. M.; Lagrost, C.; Costuas, K.; Choua, S.; Turek, P.; Norel, L.; Rigaut, S. Inorg. Chem. 2014, 53, 8172-8188; f) Mulas, A.; He, X.; Hervault Y. -M.; Norel, L.; Rigaut, S.; Lagrost, C. Chem. Eur. J. 2017 doi:10.1002/chem.201701903; g) Meng, F.; Hervault, Y.; Shao, Q.; Hu, B.; Norel, L.; Rigaut, S.; Chen, X. Nat. Commun. 2014, 5, 3023; h) Meng, F.; Hervault, Y.-M.; Norel, L.; Costuas, K.; Van Dyck, C.; Geskin, V.; Cornil, J.; Hng, H. H.; Rigaut, S.; Chen, X. Chem. Sci. 2012, 3, 3113-3138; i) Li, B.; Wang, J.Y.; Wen, H.-M.; Shi, L.-X.; Chen, Z.-N. J. Am. Chem. Soc. 2012, 134, 16059-16067.

(12) a) Browne W. R.; de Jong, J. J. D.; Kudernac, T.; Walko, M.; Lucas, L. N.; Uchida, K.; van Esch, J. H.; Feringa, B. L., Chem. Eur. J. 2005, 11, 6414-6429; b) Ibid, 6430-6441; c) Guirado, G.; Coudret, C.; Hliwa, M.; Launay, J.-P. J. Phys. Chem. B, 2005, 109, 17445; d)Roberts, M. N.; Nagle, J. K.; Finden, J. G.; Branda, N. R.; Wolf, M. O. Inorg. Chem. 2008, 48, 19-21.

(13) Note that attemps to stereoselectively close 10 to $1 \mathrm{c}$ in the solid state failed.

(14) See reviews on logic gates: a) Pilarczyk, K; Daly, B.; Podborska, A.; Kwolek, P.; A.D. Silverson, V.; de Silva, A. P.; Szacilowski, K. Coord. Chem. Rev. 2016, 325, 135-160; b) Andreasson, J.; Pischel, U. Chem. Soc. Rev. 2010 39, 174-188; c) Katz, E.; Privman, V. Chem. Soc. Rev. 2010, 39, 1835-1857; d) Szacilowski, K. Chem. Rev. 2008, 108, 3481-3548.

(15) For transition-metal based DTE systems, see: Harvey, E. C.; Feringa, B. L.; Vos, J. G.; Browne, W. R.; Pryce, M. T. Coord. Chem. Rev. 2015, 282-283, 77-86. 